\title{
Principles of form construction and their dialectical relation in the musical styles
}

\author{
Penka Pencheva Mincheva \\ Faculty of Music Pedagogy, Academy of Music, Dance and Fine Arts - Plovdiv, Bulgaria, Europe
}

Email address:

pmincheva1935@abv.bg

\section{To cite this article:}

Penka Pencheva Mincheva. Principles of Form Construction and their Dialectical Relation in the Musical Styles. International Journal of Literature and Arts. Special Issue: Musical Theory, Psychology and Pedagogy. Vol. 2, No. 5-1, 2014, pp. 61-64.

doi: 10.11648/j.ijla.s.2014020501.20

\begin{abstract}
Objects of the study are the two basic principles of the multi-voice thinking - the polyphonic - linear and the homophonic - vertical. Their effect is discussed in the various styles. The different meaning of the two main qualities of the chord is also clarified - phonism and functionality and their manifestation in the types of multi-voice musical thinking.
\end{abstract}

Keywords: Linear Multi-Voice Thinking - Polyphony, Vertical Multi-Voice Thinking - Homophony, Phonism, Functionality, Musical Theory

\section{Introduction}

As in nature, so in social life, and therefore also in art, the birth of a new element is formed on the basis of the old, it gradually takes shape, gathers energy, establishes itself; while ascensions and declines can be seen in its later being, or, on the contrary, stabilization and consolidation. This means that the story of each medium, element, property has a contradictory, spiral development.

\section{The Relation}

\section{Polyphonic-Homophonic Type of Multi-Voice Thinking}

In musical history, as early as the wake of the creation of instrumental music, the initial forms of multi-voice thinking were outlined. Its original form is a drone voice - ison (one tone, identical to the first tone of the moving voice, its octave double, or found at an octave plus a fifth), over which the melody is developed. This is the most basic polyphonic nostrum. The next, more complicated technique is the canonic appearance of a melody in each of the voices. Similar to this form of multi-voice thinking is also the imitation.

This method began to serve as an important form construction principle for the created in this way polyphonic type of multi-voice texture. On the basis of this nostrum - imitation - the highest musical form, related to the polyphonic multi-voice texture - the fugue - was established and developed. According to the principles of construction of this musical form, the main theme has to be exposed, i.e. to be reproduced sequentially in each of the voices; and after the initial (usually monophonic) sounding of the theme, each of its subsequent recurrences is followed by a new melodic formations in the other simultaneously sounding voices. The exposition is followed by the development (repercussion) and the conclusive part of the fugue.

The main driving force, guiding the development of the form of the fugue, however, was the imitation, and its prototype, the canon. The imitation was derived from the canon. The basic principle - consecutive reproduction of the initial motive of the theme in each voice but from different modal pitches is retained. When replacing some of the melodic intervals, the graph of the melodic line and the metrorhythmic structure is preserved.



Figure 1. J. S. Bach - Fuga cis moll from "Well tempered clavier", volume I, bars $1-6$

The organization of the musical material is realized on the basis of the linear musical thinking. Characteristic for this, polyphonic, way of expressing a musical thought is namely 
the simultaneous sounding of two or more relatively independent melodic voices. The sound complexes - chords, in the polyphonic type of multi-voice texture are a result of the concurrence in time of the tones from the separate melodies. This means that the sounding chord has a random character, i.e. it is not a predefined construct. Gradually, in the development of this type of multi-voice texture, more focus was placed on the essence of the sounding chord formations in terms of interval construction, but also as a bearer of a greater or lesser tension - instability, or balance - stability. In the cadencing moments of the polyphonic works of the great composers - Bach and Handel (figure 5) - the new driving force of the musical development, the new form construction principle was born - functionality of the chord progressions. Functionality is expressed through its main varieties:

- stability (tonic - T);

- instability with its two opposite characteristics non-intense instability (subdominant $-\mathrm{S}$ ) and intense instability (dominant - D), expressing special activeness, creating tangible pressure.

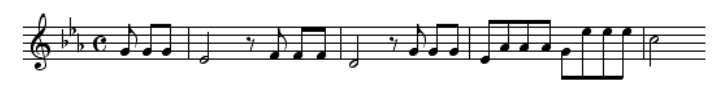

Figure 2. L. W. Beethoven - Symphony № 5, Part I, Theme I

The pulsing dramatism, the immense tension in the development of the theme is achieved through various means of expression, but the main, the distinctive is the juxtaposition of $\mathrm{D}$ and $\mathrm{T}$ with their strictly expressed functional relation.

And so, within the frame of the polyphonic type of multi-voice texture, a new type of musical thinking - the homophonic, i.e. the vertical, slowly appeared and was established. The reasoning behind it being defined as such is based in the fact that the melody - the main bearer of musical content - is clarified functionally (the changes in its stability-instability are clarified) and it is accompanied, varied, enriched through the chords. The chord in the homophonic type of multi-voice texture is a ready construct - there are 4 types of triads, seven types of tetrads; they all have methods for application, defined by clear rules.

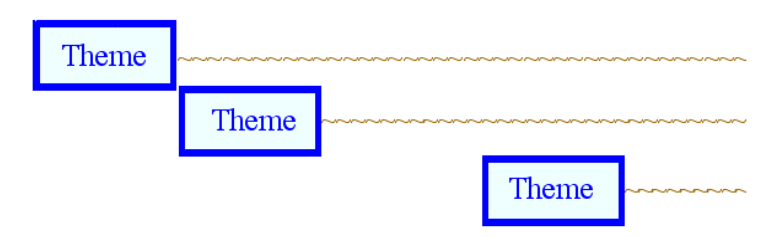

Figure 3. Polyphony, linear thinking

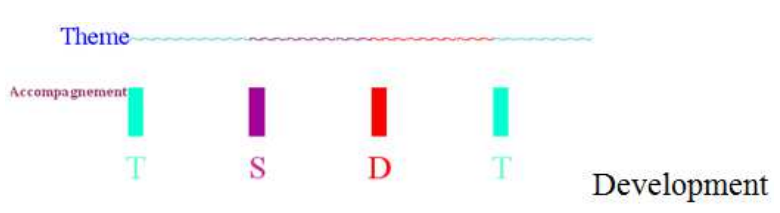

Figure 4. Homophony, vertical thinking
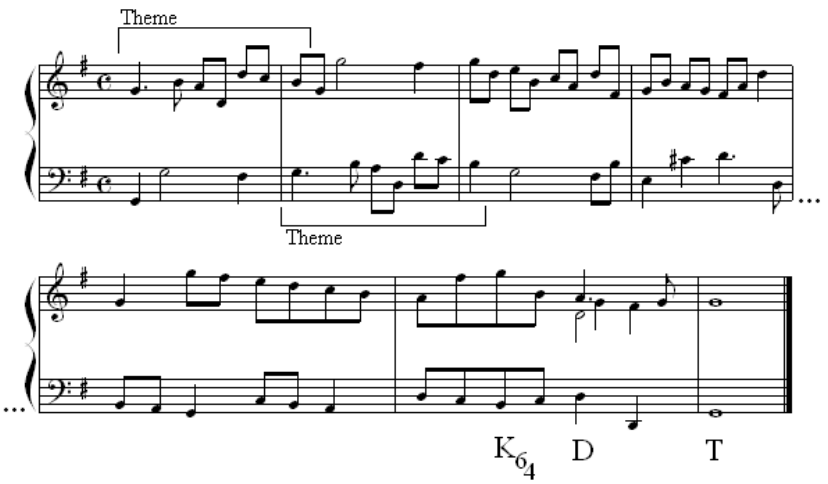

Figure 5. G. F. Handel-Fugue G dur, b. 1-4 and $17-19$
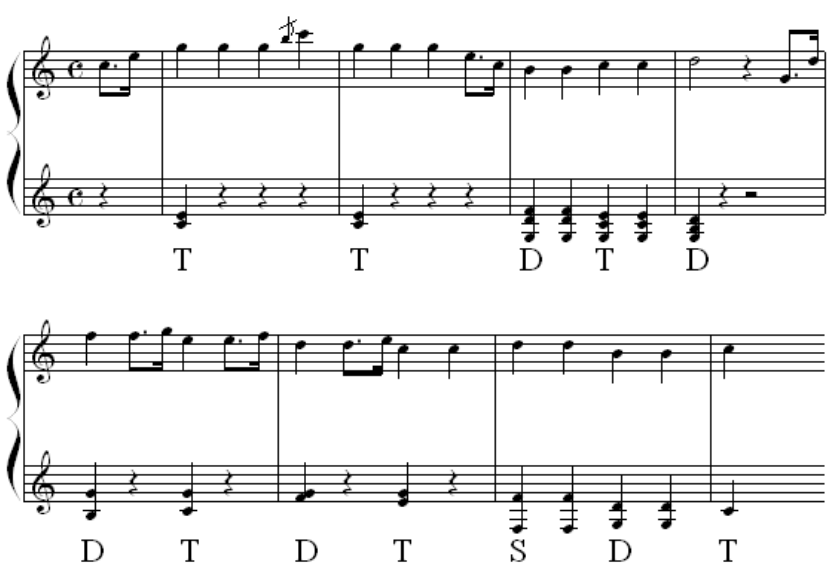

Figure 6. J. Haydn-Sonata C-dur, Part I, bars $1-8$

But as the main features of the new multi-voice style - the presence of a chord accompaniment for the melody with a strictly expressed functional dependency - are defined within the frames of the polyphonic type of multi-voice texture, so in the works of the Viennese classic composers founders of the homophonic type of multi-voice texture, individual polyphonic methods can be found with the purpose of enriching the expression:
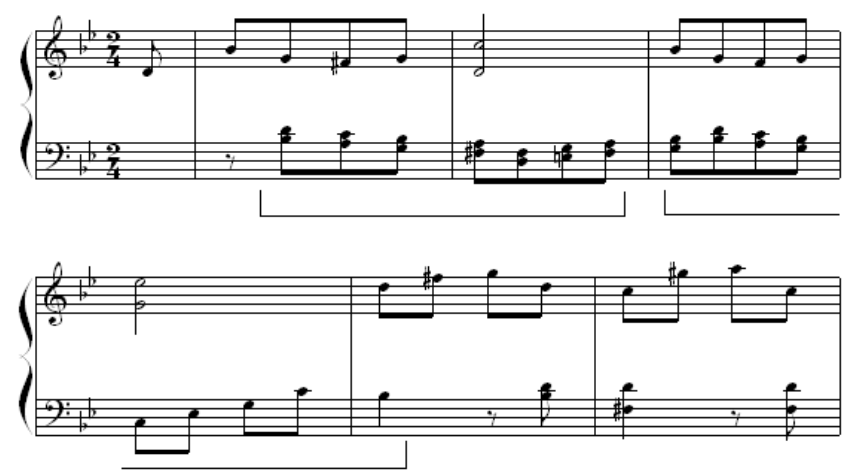

Figure 7. L. W. Beethoven - Sonata № 19, Part I, b. 1 - 6

The addition of new, supplemental, hidden voices gradually could also be seen more and more prominently in the works of the composers-romanticists. 

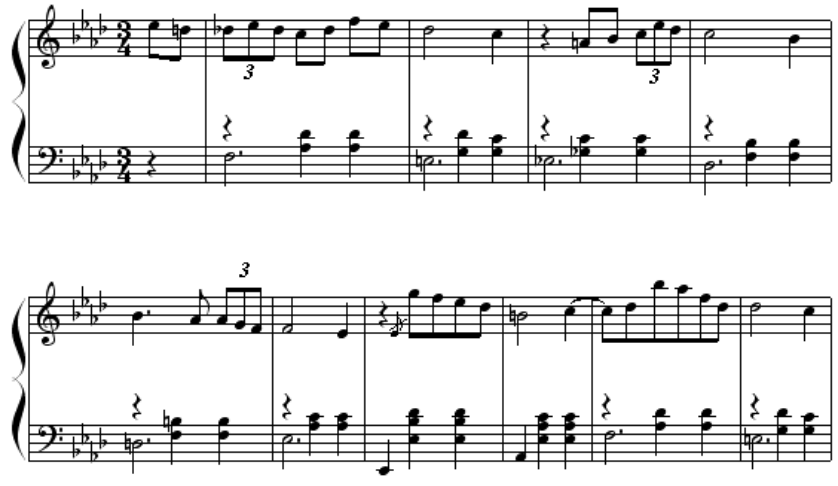

Figure 8a. F. Chopin - Waltz № 9, bars 1 - 10

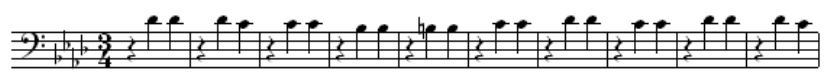

Figure 8b. - F. Chopin - Waltz № 9, bars 1 - 10, supplemental melody middle voice

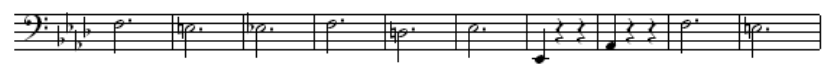

Figure 8c. - F. Chopin - Waltz № 9, bars 1 - 10, supplemental melody bass

The rich, multicolor harmony of the composers-romanticists prepared gradually the replacement of the functionallity of the assonances for the benefit of their vividness, i.e. in the next composer style - the Romanticism, the chords were more and more often used with their phonic quality. The colouristic purposes, which the composers set out - the portrayal of different sides of the multicolorful reality - imposed the appearance of polychromic chord structures.

\section{The Relation Functionality - Phonism of the Triads}

The phonism of the chords is defined by their interval structure. Precisely on the basis of their interval structure phonism - the four types of triads and the seven types of tetrads have been derived. Phonism allows for the chords to be defined also as consonants (and their variants - perfect and imperfect consonances) and dissonants (whose variants are softly and sharply dissonating assonances). These characteristics depend on the way, in which one's musical hearing has been trained to perceive and understand them (the training on its part consists of the building of a sense on the basis of the knowledge about the correlations in the number of vibrations between the sounding tones, comprising the assonance).

The functionality of the assonances is defined by the participation of the modal degrees, which form the sound construct. This means that:

a) The phonism of the assonance could be viewed in the specific mode, but also outside of it;

b) The functionality of the assonance could be defined only on the basis of its presence in the sound composition of a given tonality;

c) Phonism is independent of functionality, but functionality is in a subordinate position to phonism (for example, one augmented triad - dissonating assonance - cannot perform the function of a tonic. During the years, there have been complex, changing interrelations between the phonism and the functionality of the assonances. Phonism - preceding the appearance of functionality, had a leading role during the Baroque era and more specifically in the Baroque type of multi-voice texture. The nascency of functionality can be found even in the thick multi-voice cadencing moments in the works of Bach and Handel (figure 5).

Functionality was given a leading role in the era of the Viennese Classical School. During this period, phonism received a subjugated role. Used as a primary construction element in the accompaniment were major and minor triads, more rarely diminished chords and completely episodically - the augmented. Frequently used are also major-minor and minor-minor, the half-diminished and the diminished tetrads. The functionality of the chords had the role of a primary driving force also in the development of the musical form. It clarified, allowed for more importance to be placed on the relations of stability-instability between the tones of the melody. The layout of the chords, their logical sequence created an impression of movement, progression, increase of tension and sharp or gradual reaching of repose.

During the era of the Romanticism, the two characteristics of the chords were in a period of equality - the chords progressions were defined by their functionality, but more varied, multi-sound, polychrome sound complexes were sought. From the beginning of the 20th century, functionality fell apart and was replaced by phonism. This phenomenon can be observed in some of the works of the Impressionism, it is strongly manifested in the Expressionism, in the dodecaphony of the artists of the Second Viennese School.

The Impressionism, which originated in France and whose stylistics was established in the works of Claude Debussy, has as a leading principle in the building of a musical work the bright, short combinations of sounds in the horizontal plain and variedly sounding complexes in the vertical plain. The short tonal sequences as a melodic motif or a harmonic core are related to the portrayal of natural scenes, of natural phenomena and represent the impressions of the surrounding world as an esthetic experience. For the progression of chord structures, the main moment or the primary driving force is the colorfulness of the separate chord and the feeling of alteration of "color" nuances. This meant that functionality had also lost completely its significance as a form constructon principle. Such significance was given only to phonism - the colorfulness of the assonances. 


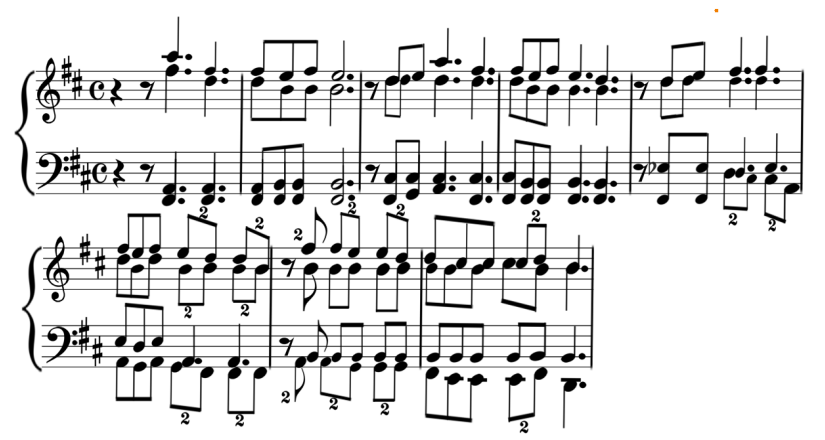

Figure 9. Cl. Debussy - "Moonlight", adaptation for a choir, b. 8 - 15

In the Expressionism style, we can see again the leading role of the phonism in the horizontal and in the vertical plain. In the works of the Expressionist authors, sharp interval combinations have been purposefuly sought (here the interval is viewed in the light of a building element of the melody, as well as of the harmony). Portrayed through these sharp interval combinations were mainly strong, painful feelings of fear, terror, despair.

Planted at the core of the Expressionism was a disillusionment of the surrounding world. In the works of the Expressionist composers, the tonality, whose fundament was exactly the functionality of the assonances, crumbled down completely. It was not a coincidence that one of the prominent representatives of the Expressionism Schoenberg - came to the idea of the twelve tone system dodecaphony, in which the functional interrelations between the tones are completely renounced. For the composers of the Second Viennese School (Alban Berg, Arnold Schoenberg and Anton Webern), the twelve tone scale consisted of equal tones, standing at a distance of the same interval - a half-tone. This sound sequence served for the construction of a melody - "series". In this melodic sequence, it was not acceptable to repeat a given tone - in the melody, nor in the harmony - before all of the twelve half-tones had been used - that would break the principle of equality of tones, highlighting, emphasizing one of them. In practice, this meant a complete renounce of functionality through the complete absence of a stability of any of the tones in the "series".

\section{Conclusions}

Phonism and functionality as properties of the sound complex are found in a synergy or a struggle for dominance in the different styles: phonism dominated over functionality during the Baroque era, had an aligned position during the Romantism and was established as the main form construction principle during the Impressionism, Expressionism, Dodecaphony; functionality was the main driving force for musical development in the Classism, was in an equal position with phonism during the Romanitc era, lost its position in the Impressionist era and was completely deconstructed in the dodecaphony.

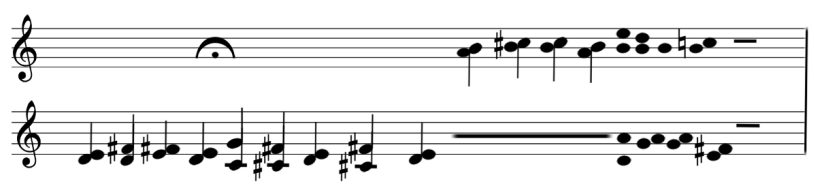

Figure 10. Iv. Spasov - "Forest charm” for a choir

\section{References}

[1] Kholopov, Y. Harmony - Theoretical Course, Moscow.1988г. (Холопов, Ю. Гармония-теоретический курс, М.1988)

[2] Protopopov, V. History of Polyphonies, Moscow.1965г. (Протопопов, В. История полифонии, М.1965)

[3] Skrebkov, S. Artistic Principles of the Musical Styles, Moscow.1973 г. (Скребков, С. Художественные принципи музикальных стилей, М.1973)

[4] Stoyanov, P. Introduction in the Theory of Music, "Kiril i Metodii" Publishing House, Veliko Tarnovo, 2001r. (Стоянов, П. Въведение в теорията на музиката, изд.”Кирил и Методий”, Велико Търново, 2001) 